\title{
Madam Fuli: An Echo of the Struggles OF Women In Bangladeshi SOCIETy
}

\author{
MD MOHIUL ISLAM \\ University of Malaya \\ mohiul.islamju@gmail.com
}

\begin{abstract}
Madam Fuli (1999) is an award-winning creation of Shahidul Islam, the director of the film. It is one of the most remarkable films in Dhallywood, the Film Industry of Bangladesh, which won the National Film Award afterwards for its storyline and stunning acting by the protagonist's (Fuli) cast Shimla. This film gave a jolt to the contemporary social systems of Bangladesh regarding our attitude towards the skin color of women and also towards our concept of beauty. Through the portrayal of various stage of Fuli's life, the director, Shahidul Islam Khokon, who is the producer and the screen-play writer of this film, takes attempts to show what are the things and incidents a girl or a woman go through in the society in Bangladesh. By putting a tagline as 'Fight for Right' the director wants to visualize the struggle of a woman with a darker skin in the society of Bangladesh where the concept of beauty is being stereotyped every now and then. Throughout the film, the character, Fuli is shown suffering for her darker skin and not being considered a beautiful person, rather as an ugly woman. However, at the end Fuli got acceptance in the society, but somehow, she had to fit herself in the mold of the society and become a woman with brighter skin. Madam Fuli (1999) actually portrays the sufferings of the women brought by the society, where the social practice set the standard of beauty and at the same time encourages the same follies and vices of the social practices that it intends to resist. This essay presents how the film depicts the status of women in Bangladesh, through a textual study of the film through feminist film theory, where the so-called informed community is literally pulled into the foundations of the same old racist notion of beauty.
\end{abstract}

Keywords: Skin color, women, beauty concept, racism, Bangladeshi society

\section{INTRODUCTION:}

Madam Fuli (Khokon 1999), a Bangladeshi film based on the very typical social context directed by Shahidul Islam Khokon. This same film was released in 1999, and was later nominated in Bangladesh for the National Film Award and further won the award. And for his amazing work in this film, Shimla, the cast of the film's lead, Fuli, received the national Best Actress Award in Bangladeshi Film.

Contemporarily, Madam Fuli got huge popularity and appreciation among the common people and also among the film critics in Bangladesh. In this film, the ups and downs in 
the life of a naive rural girl have been portrayed, and the bases of her ups and downs were social view point and society's reactions towards the tone of her skin. The movie shows how the tone/color of a person can change his/her luck for lifetime, how someone's skin tone becomes the scale his/her acceptability in the eyes of the society, especially in a society like a Bangladeshi one. Beside the fact of the skin tone of a person, Madam Fuli shows how the financial circumstance of a person becomes the base of one's adequacy in the capitalist society, where money plays the most important role to rule over anything, anyone. But, a detailed study on Madam Fuli would actually encourages that capitalist racist society in doing such things by the portrayals of the people who have dark skin tone and less amount of money in a capitalist society. Through the feminist film theory this article analyzes the film, Madam Fuli and explains how a woman actually has to fit herself into the mold set by the society to be accepted in and by the society. The study presents a discussion and analysis on how the society in Bangladesh indeed encourages the racism and capitalism in the name a revolutionary character namely, Fuli, who fights for right. The paper also offers a depiction of the condition the women in the society where they become only the option of the male gaze and a source of visual and sexual pleasure.

Through a textual analysis, this study gives a postcolonial explanation of Madam Fuli, where it has been portrayed how the racism still exists in the minds of the people and how these people are being affected by their racist point of view in every now and then. It shows how people in Bangladesh still believe the same old idea and concept beauty, that is beauty means white, imposed by the British people during their colonization almost about 250 years ago! In parallel, this very article shows how Madam Fuli depicts the social condition of containing the idea of making the women a point of male gaze, and supporting the racism and capitalism through the characters of the films.

\section{Colors and Their Cultural Meanings}

Colors are found to create definitions of various aspects in human life and provide knowledge anywhere on the world (Islam et al, 2020). Things without color sound very flat and tasteless to the human beings. Hence, it is quite common for the mankind to look for colorful things almost everywhere in nature and life. From the body to the tiny little part of nature, human minds look for variation of colors. Nevertheless, the color of the human skin has always been a point of controversy as it created division and partitions amongst the human beings. Even though interpretation and comprehension of colors differ from individual to individual. Individuals create their minds set within ninety seconds upon seeing something or someone and sixty-two to ninety percent of all judgments are conducted by color-only evaluation of items (Singh, 2006). Thus, someone's color or something has the ability to stimulate human minds and tends to have an effect on the individual or matter's decision-making.

While making a visual production, such as films, drama, tv-series, TVC, music videos or any other visual contents, protagonists are given numerous colors with unique traits that have captured the attention of analysts and academics as colors can play roles in knowledge circulation as well as establishing personalities of imagery and conceptual ideals and interpretations that endure for a prolonged duration among audiences (Darrodi, 2012). From the general sense, it might seem that, these colors are chosen and put on different characters just to create variations in the content. A color can operate in a convention-based way as an emblem that explicitly stands for something, and the shades of the colors could also establish 
abstract associations. In addition, these definitions are straightforward, rather than defined by social structures (Dansei, 2002). As per Dansei's elucidation of the connotations of the colors, a single color may have multiple meanings based on the contexts, culture, situations, geography, and social practices. The following table (Table 1) may be reserved from Dansei 's clarification of the connotations of the shades, while reflecting everything in the Western sense. It is worth noting that, because the Western concept of colors and their meanings is important for the present research, as Bangladesh's society embraces a lot of Western culture standards and ideologies due to the colonialism by the Europeans mentioned in the next section of the article.

Table 1: The connotation of the colors in the western society

\begin{tabular}{|l|l|}
\hline Colors & Connotations in the Western Context \\
\hline White & Purity, innocence, virtuous, chastity, goodness, decency, etc. \\
\hline Black & Evil, impurity, guilt, vice, sinfulness, indecency, immorality, etc. \\
\hline Red & Blood, passion, sexuality, fertility, fecundity, anger, sensuality, etc. \\
\hline Green & Hope, insecurity, naiveté, candor, trust, life, existence, etc. \\
\hline Yellow & Liveliness, sunshine, happiness, tranquility, peacefulness, etc. \\
\hline Blue & Hope, sky, paradise, tranquility, calmness, mysticism, mystery, etc. \\
\hline Brown & Earthiness, naturalness, primordiality, constancy, etc. \\
\hline Gray & Dullness, mistiness, obscurity, mystery, nebulousness, etc. \\
\hline
\end{tabular}

(Source: Dansei, 2002, p.41).

\section{SOCIAL PERSPECTIVE IN BANGLADESH TOWARDS DARK HUMAN SKIN}

From the Bengali to the Bangladeshi people, their attitude towards the dark human skin is same. In a patriarchal society like Bangladesh, women's body become a text where the beauty and aesthetics of the text are measured by the men through the external appearances and not any terms of their (women's) inner characteristics and not any other qualifications. The external appearances do not have any connection with a woman's characteristics. But in reality, the scenario is quite opposite for both man and woman. In Bangladesh, there is a proverb for judging a person, "When you see a man/woman, consider his/her appearance first, and then the mind." (Arif, 2004: 585). The appearance of person may indicate about that person's mood or profession, not his/her characteristics which actually make him/her good or bad. But in a patriarchal society like the Bangladesh's one, the women get judged by their skin tone, not by their inner or any professional qualities.

In Bangladesh the popular perception of beauty is associated with fair complexion and words for 'beauty' and 'fairness' are deemed to be synonymous. Here 'fair' is 'lovely' and 'unfair' is 'ugly'. Having a pale skin denotes a combination of all good attributes and is equated as social benchmark of aristocratic lineage, superiority and class allegiance (Khalid, 2016). In Bangladesh, if a woman has a dark skin tone, certainly she is considered as an unattractive 
ugly person from the view point of the stereotyped concept of beauty which Bangladeshis have been possessing in their minds since being colonized by the British almost about two hundred and fifty years back; even though the woman might have an attractive figure with smart appearance. They do not fit the white standards of the specular system. They wear ugliness, because all the visual representations around them reject them as ugly (Walther, 1990). This kind of reflection is found in Madam Fuli.

The wealthy are generally fair skinned. Those that aren't usually just marry a fair skinned woman and this goes on. On the other hand, the day laborers and house maids are mostly dark. Of course, it does not affect men as much as women. Women here are expected to be beautiful (which according to our society cannot be achieved unless she is fair). The dark complexion/tone of skin is not accepted by the men as a symbol of beauty for the women. But things are completely different if it happens to a man. A double standard is visible regarding the dark skin tone of man and woman in Bangladeshi society. For the women it is completely unacceptable to have dark skin color. But the men do not evoke any negative response in the same issue! The interpretation can be formulated in the following ways:

The 'Black' color signifies negative in Bangladeshi society, whereas 'White' is a positive phenomenon in Bengali culture now.

A woman with dark skin is considered as an ugly one; whereas the fairness of the skin standardizes the concept of beauty and whoever has fair skin, becomes superior and more privileged.

White is a symbol of beauty, purity, cleanliness and happiness (Arif, 2004).

Since being colonized for several times by the Europeans, people from Bangladesh believes in the meanings and priority of the colors that were set by the colonizers once. They love to see the contents of media as per their own choice too. Here color/shade of the skin of the performer plays a vital part in gaining popularity and also in characterization. Regarding the meaning of colors, the media industry as well as the society still believes in the western concept of colors.

\section{FEMINIST FILM THEORY}

Mulvey appeared to question the roles of the women in the film world, where women in the films at the then time, were often held and depicted as subordinate characters and were not even in the center of the films. Laura Mulvey raised her finger towards the gendering of the women in the films and making them as the source of visual and sexual pleasure for the audience and to some extent within the cinema. Although Lura Mulvey addressed these issues among the Hollywood films. She found that Hollywood films have the abilities to create a pleasure for the male audiences by placing the women/female characters in such a place where the audiences have the option to gaze at them (Mulvey, 1989). This gaze may create an erotic pleasure among the audiences and to some extent may lead them to some type of unusual aspects like perversions, voyeuristic peeping Tom with a sort of erotic sense. In these types of cinemas, where male actors rule over women, Johnston in Thornham (1999), has disputed the portrayal of women in films where the masculine mentality against women dominates, women are portrayed as the way men want them to be depicted (Islam \& Akter, 2020).

With regard to the representation of women in the films, Mulvey created the notion that women are the choice of male gaze, she coined the word" to-be-looked-at-ness, "which 
suggests that women in the films are just" exhibitionist erotic objects on view, supplying the straight, male, voyeuristic viewer with visual gratification (Cristian \& Dragon, 2008, p. 90).

\section{METHODOLOGY}

The paper attempts to reveal how Madam Fuli (1999) has portrayed the situation of the women in the patriarchal social system. Besides, it also reveals how stereotyping is done in the Bangladeshi society through the skin color of the women. To achieve this goal, this paper adopts the textual analysis as an approach for the study where the film, Madam Fuli (1999) has been studied as a text. A qualitative content analysis that involves a larger variety of text testing with many problems or statistics may also accomplish the same kind of goal. But since the emphasis is only on the interpretation of the one character for this very study, this study has followed textual analysis as the research methodology in this regard. Although, the study analyzes the relationships of the focused character with the other ones to get an intensive idea of treatment of the women that has been portrayed. Furthermore, because the document does not convey or describe itself, textual research is carried out by taking into account the sociopolitical, economic, institutional and cultural background of the language (Bennett, 1982). And except for its speaker or creator, the importance of the text can be found among its audience (Staiger, 1992).

The current study has been patterned to answer the portrayal of the women regarding their treatment by the male dominated society in Madam Fuli (1999), directed by Shahidul Islam Khokon. This research has been turned into a qualitative library review through the method to textual interpretation of the film, where data has been obtained from scripts or transcripts of films, posts, blogs, etc (Islam \& Akter, 2020). Since doing library research is not a matter of luck by chance, but in this process, even without understanding what kind of references he / she may encounter when doing the analysis, one has control of the whole process (George, 2008).

A four-step data collection (Fig 1) has been conducted to implement this analysis, the following graph was followed to produce the data needed for this very analysis.

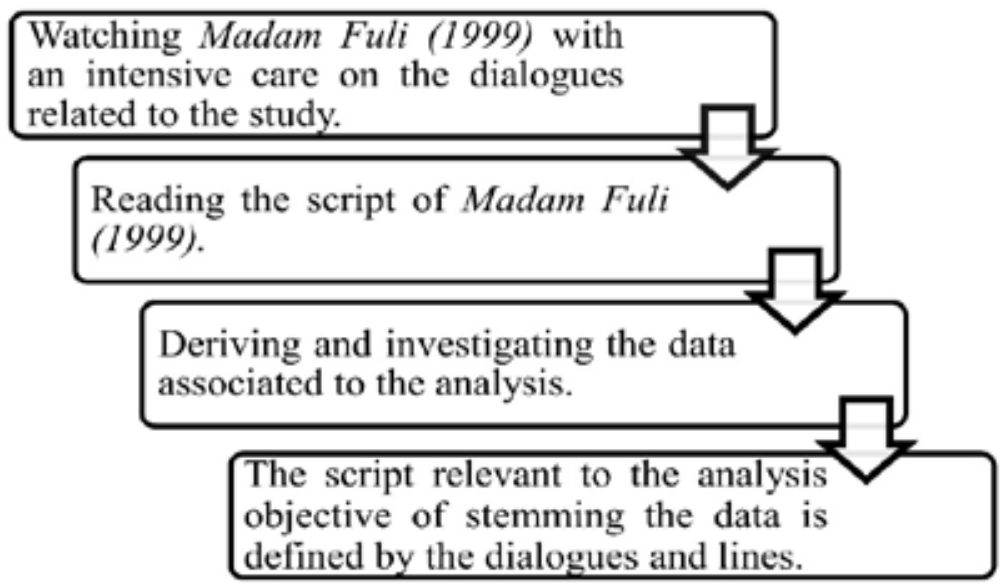

Figure 1: The process of data collection (Latif, 2016; Islam \& Akter, 2020) 
In a four-step method (Fig 2), data analysis for this thesis has also been performed. The following protocol has been maintained for the study of extracted results.

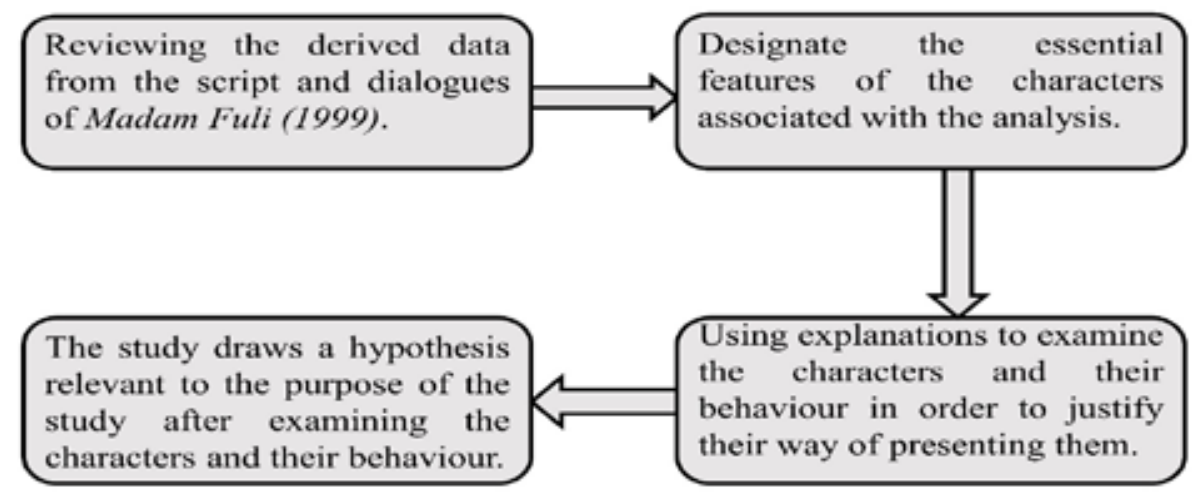

Figure 2: The process of data analysis for the study (Latif, 2016; Islam \& Akter, 2020).

The entire film is mostly analyzed through the feminist film theory, as the study intends to offer a discussion on the suffering of the women in Bangladeshi society regarding their tone of skin. Basically, the three stages of the Fuli's life (Fig 3) are the focal point that has been analyzed through the feminist film theory coined by Laura Mulvey. The original character of Fuli, her relationship with her husband, and her transformation to Shimla, these three stages are being analyzed by a textual analysis of the film. In these stages, Fuli has encountered with various experiences which are entirely different from one another and which gives an indication of the challenges that women with darker skin tone face in the society of Bangladesh. Dialogues delivered by the various characters in film, are also considered as the tool of abuses and treatment done towards the women.

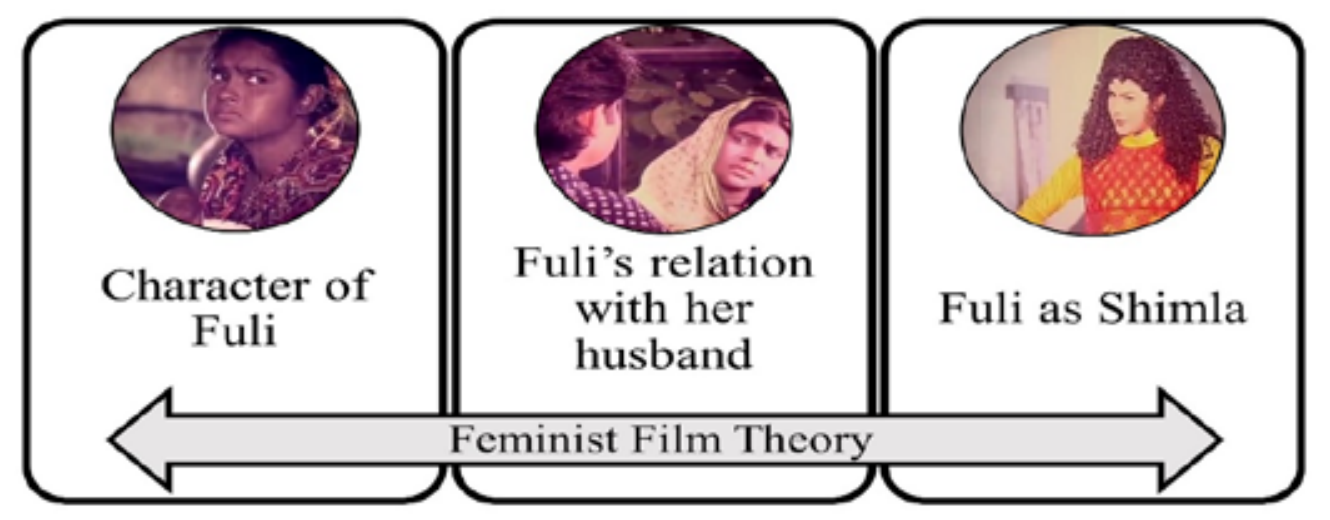

Figure 3: The framework of the study.

\section{Story-line of Madam Fuli}

In the very beginning of Madam Fuli, a rich family in Dhaka is shown where the owner of the family is a paralyzed person. A step brother of the owner of the house, namely, Karam Ali, 
(role played by late Humayun Faridi) came to visit there with a plan to fetch the property of that paralyzed owner and to marry the owner's wife, whom Karam Ali used to love. Karam Ali killed his step brother, the owner of the house, by pushing him down from the stairs. But the house maid saw the murder and fled away for her own safety, as the murderer did not want to keep any witness alive. The maid fled away with the little baby of her master, and eventually, by the turn of life the little becomes Fuli, who in future turns into Madam Fuli.

The simple life of Fuli in her village became intolerable because of her youth and color of her skin. She had a darker skin tone (Fig 4). As a result, due to her dark skin tone, Fuli started losing her acceptance to the society. And besides, she grew up as a very liberal person. Things started going worse when Fuli had to get married with a young man who lived in a city, and was forced to marry Fuli. The forceful marriage, getting refused to be recognized as a wife by the husband, these became the common parts of Fuli's everyday life. Though even before the marriage, both Fuli and her mother (the maid who was known to Fuli as her mother) had a doubt regarding finding someone who would marry a girl with such dark skin. But things became worse for Fuli after her marriage with Sohel, a modern educated young man. She was continuously bullied and verbally abused by her own husband because of her dark skin tone. When Fuli's husband, Sohel took her to the city life, he introduced Fuli to everyone there as one of his house-maids! Gradually Sohel's friends came to know the real identity of Fuli and left Sohel because of such attitude towards his wife. As a result, Sohel wanted to leave Fuli at her village, but on the way, they had an accident and Sohel informed everyone that Fuli died in an accident. But Fuli did not die. Eventually a rich lady with her daughter rescued Fuli from the bank of the river and Fuli's husband Sohel was in love with this daughter. And this lady was the real mother of Fuli! Gradually, with of the the lady Fuli transformed herself into a modern, well-educated super model, exotic dancer. Dark skinned Fuli turned into a fair, bright skinned Shimla/ Madam Fuli. And Sohel again fell in love for Madam Fuli/Shimla. Eventually, by many turns and burns of life, at the end of the film, Shimla (Fuli) revealed her real identity and got accepted by her husband.

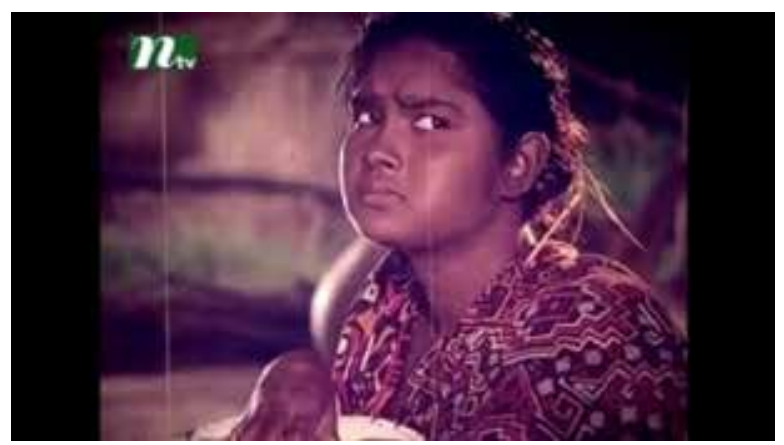

Figure 4: Fuli's initial skin complexion.

\section{Role of Skin Color in Madam Fuli}

Some detailed explanations and criticism of some particular scenes and incidents in Madam Fuli which are directly or indirectly related to color and skin of human body bring out the issue of racism in the film along with the portrayal of the Bangladeshi society's attitude towards the tone of one's skin (which is discussed in the next part of the study). Besides, the domination by the capitalists in the society is also visible in this very film. The concept of beauty through whiteness has been established by visualizing variant sphere of Fuli's life, by 
the issue of the color tone of one's skin; which has a similarity with Toni Morrison's famous novel, The Bluest Eye, where the exactly same racist beauty concept has been portrayed through the incidents of an African girl namely Pecola. Due to having a dark skin tone, Pecola was neglected everywhere in her society, in her locality, in her family. As a result, the whiteness of skin became the standard of beauty to Pecola. Pecola's society made her understand that, having a white/brighter skin tone would be the first and foremost quality of someone to be recognized as beautiful. The exactly same conception about beauty is shown here in Madam Fuli. By showing different incidents of Fuli's life, the existing concept of beauty has been portrayed in Madam Fuli. Besides, financial solvency has also been set here in this film as a prior criterion to be accepted by the society.

\section{THE CONCEPT OF COLOR IN THE SOCIETY OF BANGLADESH}

Black is the darkest color among the hierarchy of all colors. It is the darkest one from its absorption of all lights; it always denotes some denial approaches to all aspects in all societies because human beings believe that black usually eclipses all kinds of positive entities like daytime, virtue, lights etc. On the other hand, white, the opposite of black is the brightest of all colors from its reflections of all visible rays of light, is treated as the symbol of sacredness, purity, innocence, honesty, power, etc. all over the world (Arif, 2004). These two concepts of cultural artifacts are applied to describe the human body; and things get severe and more serious when the body is a woman's one! In Bangladesh, women's appearance is described through the colors or one can say through the complexion of a woman's skin; whether it is bright or dark. The human body, specially the women's ones become a living text, where in most of the time, the text is read and analyzed by the males through the existing concepts and meaning of colors and skin tones. The women get recognized by their skin tone by the men. In the society of Bangladesh, the dark complexion of a woman's body creates a negative signification in the society and white creates a positive one (Arif, 2004).

Considering the issue of creating identities the people from both two common religions, Hindu and Muslim, in Bengali culture, are a mixed phenomenon with the significance of uniqueness that belongs to the proto Australoid ethnic group (Arif, 2004). According to the so-called western beauty concept, they are not beautiful. They have different skin colors, which includes black, light yellow and brown in Bangladesh. Through the two hundred years of being colonized by the British and the neighborhood of India, where 'Black' is considered as the color of darkness and symbol of unprivileged people; Bangladesh has also taken it granted that dark skin toned people have the significance of being negative.

The origin of Bengali culture plays an important role in creating the meaning of the colors from the social context. The majority of the population belongs to the proto-Australoid ethnic groups; some of them are Mongoloid race and a small number are of Aryan origin (Arif, 2004). Maria Schetelich describes the extent of the prejudice regarding the meaning of colors in Southern Asian sub-continent which is strongly visible in societies of Bangladesh,

Criterion for the qualification of a phenomenon as good was the relation to the society, religion and cult of the Vedic Aryan. As good the Vedic hymns classify the light, bright, golden colored, the sun, heaven and large space, wellbeing and security, the right (religio-moral) norms and behavior (suvrata), the arya of the aryabarna Indra. Soma and their adoration by sacrificing them, to the spare of evil belongs darkness, the night, the black color, the unbelieving and non-sacrificing (to 
Indra Soma) people, the dasa, the dasyu, a bad or no-vrata all (apanya or avrata), the 'black skine', the depth, the danger, narrowness.

(Schetelic, 1990: 245).

When the discussion is about the color tone of a person/human, especially of a woman, the woman's body turns into a text to be discussed and criticized. And here the concept of the meaning of the colors among the minds of the men becomes the catalyst to continue the gossip and discussion. And a 'woman's' body is considered as a text in every society, as it creates communication approach with others, especially the men, with the help various catalysts like color, skin tone (Arif, 2004).

\section{Instances of Racism in Madam Fuli:}

The director, Shahidul Islam Khokon has directly visualized the racism that is clearly visible in our society among the people of different profession and locality (both in rural and urban areas). Through various incidents in Fuli's, the director visualizes the racist mentality/ psychology among the people of Bangladesh. And by portraying the of racism through different incidents in Fuli's life, the director has made different character play different roles with their racist minds which is actually the portrayal of the existence of racism in every single corner of the society.

The issue of racism becomes very visible for the first time in Madam Fuli when Fuli is shown as a grown-up young woman with a dark skin. She is portrayed as an unlettered, stereotyped rural woman, who is not worried about her age, her limitations in a patriarchal society. She is shown as a woman who is completely unaware of her health, who is not concerned about her hygiene, who does not get herself cleaned before going to the bed, who does not take bath regularly and who remains filthy throughout the whole day. This certain type of portrayal of Fuli's character indicates her as an uncivilized person; and situations get worse for Fuli and her mother(fake) when they both think of Fuli's dark skin and her marriage. Both Fuli and her mother (fake) wonder that who would marry such a dark and uncivilized girl! Even Fuli considers herself as a rural ghostly creature due to having a very dark skin complexion. Such inferiority complex of both Fuli and her mother regarding Fuli's dark skin is actually the outcome of the society's view point towards the darker skinned people which has already been mentioned.

Though Fuli has strain about finding someone to get married with; finally, she gets the chance to marry the son of a rich family in her village, who is a handsome young man named Sohel, who turns to be the hero of Madam Fuli. But it was a forceful marriage. Sohel did not agree with his father to marry Fuli, as she had a very dark skin and no literacy. Even after the marriage, Sohel did not accept Fuli as his wife. He refused Fuli again and again just because of her dark skin. Sohel used to call Fuli as an uncivilized 'rural brute' (Khokon, 1999) whenever Fuli wanted to get close with him as his wife. Fuli did not get the proper respect and recognition as a wife by Sohel even at a time she dressed like a modern heroine when she had found Sohel gazing at a poster. That night Fuli dressed like that heroine in the poster to impress her husband, but still she was refused to get the recognition of repeatedly by Sohel; because she had a darker skin complexion. The skin color became more important to Sohel than Fuli's emotion and love for him. Sohel only cared for Fuli's skin color, neither her emotion nor her physical beauty. 
When Fuli went to the city with her husband, again Sohel refused to introduce her as his wife in front of his friends, rather she was introduced her as a house-maid (Fig 5) and she was forced to do all house-hold things. And Fuli had to face such situation just because of her darker skin!

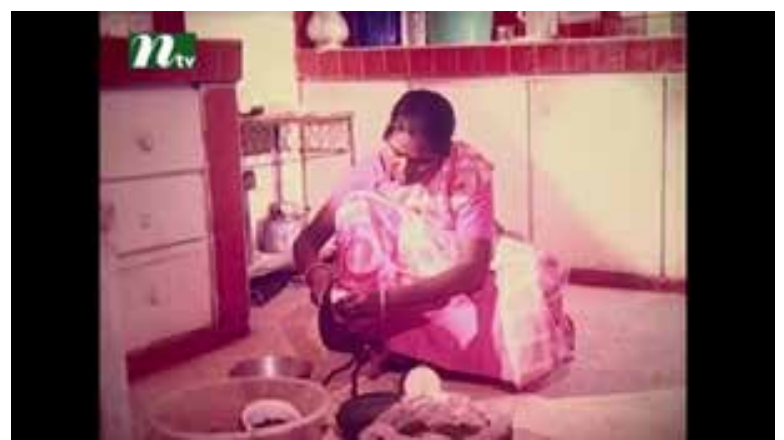

Fig. 5: Fuli, working as a housemaid

The most striking part of this film is, when Fuli eventually got a chance to be groomed up and transformed herself into a modern lady with a strong financial backup, a brighter skin, decent accent in English, contemporary western stylish attires. She even changed her name and got a new identity as Shimla! And then she started having a relationship with Sohel, her real husband, but with a different identity (Fig 6). Though Sohel was already engaged with another lady! Here, Shimla's (who was Fuli previously) acceptance by Sohel can be interpreted by two facts, one can be her strong financial background and another can be her brighter skin tone. And by spotting a light on Sohel's previous attitude towards Fuli, makes it clear that it was the brighter skin and so called modern life style of Shimla for which Sohel actually fell for her.

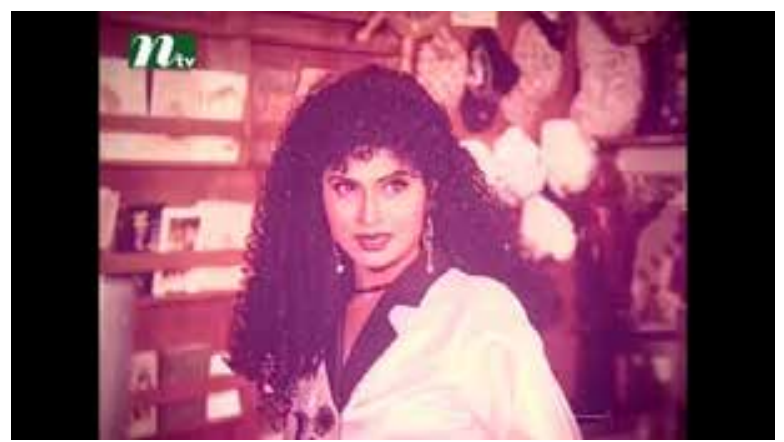

Figure 6: Fuli in Western Dress, turns herself into Shimla

Instances of racist psychology are visible even in the scenes for comic-relief in Madam Fuli. One comic-relief scene bears a concrete example of racism along with the interpretation of colors done by the people of Bangladesh, which has already been discussed in one the previous chapters. The character named, Karam ALi, used to love Salma, but he could marry her. And Karam Ali still wants to marry Salma even though Slama has become older now with white hair. So, Karam Ali wanted to do something magical with the help of black magic done by an imposter saint. The imposter saint asked Karama Ali to collect Salma's hair to do the magic and Karam Ali brought a white one. Then the pseudo saint informed karam 
Ali that, the white hair would not work for the evil black magic. Because the white does not do anything evil and illegal, where the black is stereotypically perfect to do such evil deeds!

\section{Madam Fuli, containing Racism, rather than Resistance:}

Madam Fuli, with a tag line as, "fight for right", seems a very social film, showing/visualizing the stereotyped perception of the color of man and woman in the contemporary society of Bangladesh; where in most of the films in Bangladesh, women are being portrayed as a good wife with submissive tone or a virtue of sacrifice (Al Sire, 2014). But, unfortunately, Madam Fuli itself carries the same old stereotyped essence and philosophy of racism towards the skin color of women, especially to those who have a darker skin; the philosophy that the people of this sub-continental region believe in regarding the concept of beauty, that is a beautiful girl or woman has to be brighter skinned.

From the very surface level of the interpretation of this very film, it might seem that this film shows the social flaws and moral degradation of the contemporary people. But the inner meaning can be turned into completely different way. On the other side of the coin, this movie actually nurtures the seeds of racism in it. It waters into the route of the plant called racism.

A deeper thought on some particular scenes of this film will definitely make people realize that how Madam Fuli is nurturing (possibly unknowingly) the stereotype concept of beauty which is a racist one. In one scene, when Fuli was roaming around with her husband, Sohel, she expressed her desire to be a woman with a skin that would have the color like milk, so that she would be more beautiful and attractive to her husband. Here, Fuli is having such a concept of beauty that, a beautiful girl/woman has to be a white skinned one to get loved by her husband. Her inner feelings and emotions are not enough to get a place in her husband's/beloved's mind. The brighter color of skin gets more importance than one's love, feelings and emotions. And this is the exact idea that this very film, Madam Fuli is portraying.

A vast dispute can be discussed regarding the ending of Madam Fuli. In the marriage scene of Sohel, Shimla reveals her real character as Fuli and she does it by removing all the dark makeovers from her face (Fig 7). She reveals herself as Fuli with a brighter skin tone and eventually gets accepted by her husband. So, it is only the whiteness and brightness of a woman's skin which brings her the acceptance to all, which makes her as a beautiful woman. When Fuli revealed her identity, she was wearing a veil; she took off that veil and appeared in modern western attire with white/bright skin (Fig 7) and got accepted and recognized as a wife by Sohel! The whole story could have been plotted in a different way. Especially in the scene when Fuli got groomed up and got loved by her husband. It could have been shown that Fuli's bright skin is nothing but just a makeover; it could have been plotted in such a way that, Simla revealed her identity as Fuli by removing the brighter makeover of her skin and got accepted by her husband with her real skin tone. But the director has made Fuli accepted by her husband when she was having a brighter skin; and this carries the message of the importance of having a brighter skin to be more beautiful. And this is nothing but the sense of racism in mind. 


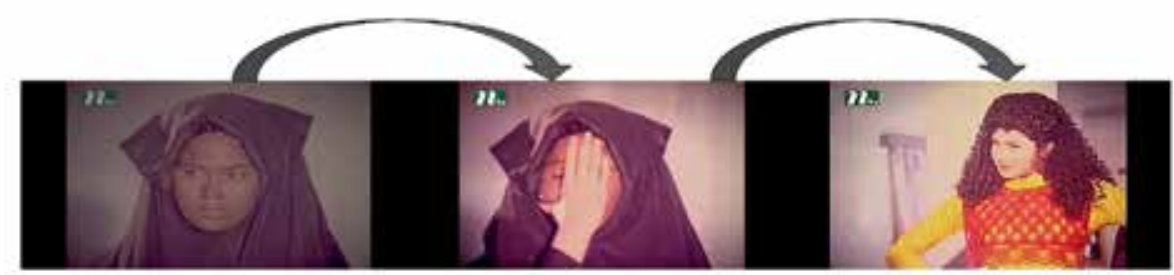

Figure 7: Transformation f Fuli: Fuli in darker skin, removing the dark makeover and how Fuli was accepted by her husband.

At this juncture, a question may arise regarding the reasons behind such portrayal of plot in Madam Fuli. Because it is expected that, a mass medium like film should carry messages which would show the vices and follies of the society and also would create respect towards every single human being, not to any particular type or group of people. But here in Madam Fuli, the so-called beauty concept has been portrayed, which reveals the crippling effects of white standards of female beauty on the young males; just like Toni Morrison has done the same portrayal in her novel The Bluest Eye (Walther, 1990: 776). And thus, Madam Fuli creates the sense of beauty, to be more specific, the white standard of female beauty in the minds of its audiences and spectators. Because the movies are the primary vehicles to transmit these kinds of images and conceptions for public consumptions (Walther, 1990), as the audiences love to be like the heroes and the heroines of the films. And this idea is also displayed in Madam Fuli when Sohel was gazing at a film poster and that Fuli dressed like a film heroine to impress her husband. Through this very portrayal and the character of Madam Fuli the film makes it visible that how the society want the women to be. Regardless to any other quality, the society wants the women to have the slim figure with white/brighter skin to be looked more beautiful and accepted as a beautiful woman by the society.

\section{CONCLUSION}

Madam Fuli is an outstanding creation of the portrayal of a woman's fight for her rights in a male dominated society, whereas most of the films in Bangladesh are made with male dominant storyline; where images of women are being portrayed as a good wife or a virtue of sacrifice (Al Sire, 2014). But Fuli's fight for her rights gets concealed by the last scene of the film where Fuli gets accepted by her husband with a white/brighter skin, not with her original skin. The director, with a tremendous success has been able to portray the stance of the women with darker skin in the society of Bangladesh, where they are being stereotypes every now and then regarding their skin color, their body shape and positions in the family, as well as in the society. Through the portrayal of Fuli's life, the film strongly carries the essence of racism in our society where being white is the ultimate standard of beauty. In Bangladeshi media- be it electronic or print- the commercial adverts of fairness products invariably projects that a woman's beauty, intelligence, happiness or success solely depend on the color of her skin. All these adverts unequivocally portray that a dark-skinned girl is undesirable, unworthy, unwelcomed, unhappy and after using a magical skin whitening cream all her dreams come true- she gets noticed, gets job, gets success, gets self-confidence 
and gets married with another white skinned handsome guy (Khalid, 2016). Thus, Shahidul Islam Khokon's Madam Fuli (1999) becomes and an extra-ordinary portrayal of the women's sufferings in their everyday life both in their home along with in their workplaces.

\section{REFERENCES}

Al Sire, S. (2014). Agnee (The Fire): Portrayal of Women in Bangladeshi Cinema. European Academic Research, 2(4), 5747-5760.

Arif, H. (2004). Womans body as a color measuring text: A signification of Bengali culture. Semiotica, 2004(150), 579-595.

Ashcroft, B., Griffiths, G., \& Tiffin, H. (2013). Post-colonial studies: The key concepts. London: Routledge.

Bennett, T. (1982). Text and social process: The case of James Bond. Screen Education, 41. 3-14.

Bhowmick, B. C. (2009). Women on screen: Representing women by women in Bangladesh cinema. Dhaka: Bangladesh Film Archive

Bordwell, D., \& Thompson, K. (2004). Film art: An introduction. New York: McGraw-Hill.

Cormier-Hamilton, P. (1994). Black naturalism and Toni Morrison: The journey away from self-love in the bluest eye. Melus, 19(4), 109-127.

Cristian, R. M., \& Dragon, Z. (2008). Encounters of the Filmic Kind. Szeged: JATEPress.

Dansei, M. (2002). Understanding media semiotics. New York: Oxford University Press Inc.

Darrodi, M. M. (2012). Models of color semiotics. (Unpublished doctoral dissertation). The University of Leeds.

George, Mary W. (2008). The Elements of Library Research. New Jersey: Princeton University Press.

Hall, S. (1997). Representation: Cultural representations and signifying practices. Vol. 2. London: Sage.

Hill, J., Gibson, P. C., Dyer, R., Kaplan, E. A., \& Willemen, P. (Eds.). (1998). The Oxford guide to film studies. Oxford: Oxford University Press.

Islam, M. M. \& Akter, N. (2020). Disney's Aladdin (2019), The old rum in the new bottle: stereotyping gender and race. Jurnal Ilmu Komunikasi. ULTIMACOMM 12(1), 72-87.

Islam, M. M., Adnan, H. M., Omar, M. A. M., \& Akter, N. (2017). Meaning of the colors in the portrayal of the animated characters: a structuralist-semiotic content Analysis of Tom and Jerry. Malaysian Journal of Media Studies, 19(1\&2), 43-56.

Khalid, S. A. (2016, June 23). 'Unfair and Ugly': Skin Whitening Adverts and Virulent Racism. The Daily Observer. Retrieved from http://www.observerbd.com/2016/06/23/157795. php

Khokon, S.I. (1999). Madam Fuli. J. K. Movies. Retrieved from https://www.youtube.com/ watch?v=Wz25ncQ9qUo

Moses, C. (1999). The blues aesthetic in Toni Morrison's the Bluest Eye. African American Review 33 (4), 623-637.

Morrison, T. (1999). The bluest eye. London: Random House.

Morrison, T., \& McKay, N. (1983). An interview with Toni Morrison. Contemporary Literature, 24(4), 413-429. 
Moore-Gilbert, B. J. (1997). Postcolonial theory: Contexts, practices, politics. New York: Verso Books.

Mulvey, L. (1989). Visual pleasure and narrative cinema. In L. Mulvey (Ed.) Visual and other pleasures (pp. 14-26). London: Palgrave Macmillan UK.

Rahman, A. (2013). The changed and unchanged situation in the representation of women in contemporary cinema. Humaniora, 25 (2), 175-183.

Singh, S. (2006). Impact of color on marketing. Management Decision, 44 (6), 783-789.

Smelik, A. (2016). Feminist film theory. Nancy Naples, Renee C. Hoogland, Maithree Wickramasinghe and Wai Ching Angela Wong, (Eds.), The Wiley Blackwell encyclopedia of gender and sexuality studies (pp. 1-5). , London: Wiley Blackwell,

Staiger, J. (1992). Interpreting films: Studies in the historical reception of the American cinema. New Jersey: Princeton University Press.

Taylor, P. C. (1999). Malcolm's conk and danto's colors; or, four logical petitions concerning race, beauty, and aesthetics. The Journal of Aesthetics and Art Criticism, 57(1), 16-20.

The Sociological Cinema. (n.d) Stereotypes: A Fundamental Concept for Teaching Sociology. http://wwwthesociologicalcinema.com/

Thornham, S. (1999). Feminist Film Theory: A Reader. Edinburgh: Edinburgh University Press.

Walther, M. (1990). Out of sight: Toni Morrison's revision of beauty. Black American Literature Forum, 24 (4), 775-789.

Wong, E. F. (1990). On visual media racism: Asians in the American motion pictures. University of Denver. 